\title{
Efektivitas Layanan E-Counseling dalam Membantu Permasalahan Siswa Selama Masa Pandemi Covid-19
}

\author{
Mardy Handika, Herdi Herdi \\ Program Studi Magister Bimbingan dan Konseling, \\ Fakultas Ilmu Pendidikan, Universitas Negeri Jakarta \\ *Corresponding Author. Email: Mardyhandika_1108820006@mhs.unj.ac.id
}

\begin{abstract}
The purpose of this study was to describe the effectiveness of ecounseling services in helping students' problems during the Covid 19 pandemic. The method in this study was a literature study, namely by collecting reading material from various scientific articles and then comparing theories and research results, which were then analyzed descriptively. . Based on the results of a literature study conducted that the implementation of online counseling (ecounseling) is effective in helping the problems faced by students, where during the Covid 19 pandemic there are many obstacles or problems faced by students so that this matter needs to be responded to by BK teachers / Counselor through the provision of online-based counseling services (e-counseling).
\end{abstract}

Abstrak: Tujuan penelitian ini adalah untuk mendeskripsikan efektivitas layanan e-counseling dalam membantu permasalahan siswa selama masa pandemi Covid 19. Metode dalam penelitian ini adalah studi literatur yaitu dengan mengumpulkan bahan bacaan dari berbagai artikel ilmiah lalu membandingkan teori serta hasil penelitian, yang selanjutnya di analisis secara deskriptif. Berdasarkan hasil studi literatur yang dilakukan bahwa pelaksanaan konseling secara online (e-counseling) efektif untuk membantu permasalahan yang dihadapi oleh siswa, dimana pada masa pandemi Covid 19 ini banyak hambatan atau masalah yang dihadapi oleh siswa sehingga hal ini perlu direspon oleh guru BK / Konselor melalui pemberian layanan BK berbasis online (e-counseling).

\section{Article History}

Received: 02-07-2021

Revised: 17-07-2021

Accepted: 06-09-2021

Published: 05-10-2021

\section{Key Words:}

E-counseling, Students' Problems.

\section{Sejarah Artikel}

Diterima: 02-07-2021

Direvisi: $17-07-2021$

Disetujui: 06-09-2021

Diterbitkan: 05-10-2021

\section{Kata Kunci:}

E-counseling, Masalah Siswa.

How to Cite: Handika, M., \& Herdi, H. (2021). Efektivitas Layanan E-Counseling dalam Membantu Permasalahan Siswa Selama Masa Pandemi Covid-19. Jurnal Paedagogy, 8(4), 506-511. doi:https://doi.org/10.33394/jp.v8i4.3948

\section{Pendahuluan}

Peranan teknologi informasi pada aktivitas manusia pada saat ini saat ini sangat besar. Hal ini dipengaruhi oleh semakin besarnya perkembangan teknologi itu sediri dan juga merupakan jawaban atas kebutuhan manusia saat ini yang semua aktivitas harus dilakukan secara online akibat dari meningkatkatnya kasus Covid-19 di indonesia bahkan dunia. Teknologi informasi telah menjadi fasilitas untuk setiap kegiatan manusia diberbagai setting kehidupan termasuk dunia pendidikan khsusunya pelaksanaan Layanan Bimbingan dan Konseling yang salah satunya bisa dilakukan dalam bentul layanan E-Counseling. Hal yang sama disampaikan oleh Hafid (Triyono, Febriani 2018) mengatakan Kegiatan bimbingan dan konseling di sekolah merupakan salah satu komponen penting dalam pendidikan yang memanfaatkan teknologi informasi. Penguasaan teknologi informasi bagi seorang guru BK/konselor merupakan suatu keharusan yang tidak bisa di tinggalkan lagi selain dari tuntutan perkembangan zaman juga merupakan jawaban atas kebutuhan pada saat ini.

Beberapa faktor yang mempengaruhi pentingnya teknologi informasi dalam bimbingan konseling yaitu: pertama karena perkembangan era globalisasi yang meningkat sehingga menuntut seorang konselor dalam menggunakan teknologi informasi. Kedua karena 
berkembangnya teknologi informasi mampu membantu konselor dalam melakukan layananlayanan bimbingan konseling tidak hanya secara langsung tetapi bia juga dengan tidak langsung yaitu layanan berbasis E-Counseling seperti konseling melalui video phone, e-mail, chating, webcam, jejaring sosial, dan sebagainya dengan tetap memperhatikan kode etik dalam bimbingan konseling. Yang ketiga kondisi saat ini (masa pendemi covid-19) yang memang menuntut adanya pelaksanaan kegiatan khusus nya konseling secara online (ECounseling). (Husni Abdillah, Punaji Setyo Sari, Blasius Boli Lasan 2020) Mengatakan dalam penelitiannya bahwa Pandemi Covid-19 menandai era penggunaan online sebagai media pembelajaran komunikasi, termasuk layanan konseling. Konselor Sekolah wajib menggunakan TIK sebagai bentuk adaptasi belajar bersama siswa.

Harapannya bagi konselor supaya mampu menerapkan system yang baik dalam teknologi informasi sehingga layanan-layanan bmbingan konseling bisa diterapkan secara komprehensif. Pesatnya perkembangan teknologi dan luasnya informasi menuntut dunia BK untuk menyesuaikan dengan lingkungan agar memenuhi kebutuhan masyarakat. Walaupun kenyataannya, konselor dan tenaga pendidik lainnya masih banyak yang buta akan teknologi seperti internet, maka disini perlu adanya peningkatan komptentensi guru BK/Konselor dalam pemanfaatan teknologi. Hal ini didukung oleh pendapat yang disampaikan oleh (Triyono, Febriani 2018) Agar teknologi bisa dimanfaatkan secara optimal maka tidak akan terlepas dari kemauan, pengetahuan, dan keterampilan guru BK/konselor dalam memanfatkannya untuk proses pelayanan. Sehingga dengan adanya peningkatan kompetensi tersebut pelaksanaan layanan $\mathrm{BK}$ berbasis E-Counseling dapat diselenggarakan dengan efektif dan efisien.

\section{Metode Penelitian}

Penelitian ini menggunakan metode kajian pustaka dengan mengumpulkan bahan bacaan dari berbagai artikel ilmiah lalu membandingkan teori serta hasil penelitian mengenal efektivitas pelaksanaan layanan E-Counseling selama masa pandemi Covid-19. Sumber data yang digunakan berasal dari data sekunder, dimana data sekunder tersebut dikumpulkan melalui buku teks, jurnal ilmiah, perodical (Nazir, 2014; Asmuni, 2020), website, dan sumber-sumber lain yang relevan dengan masalah penelitian. Data yang dikumpulkan selanjutnya dianalisis secara deskriptif kualitatif.

\section{Hasil Penelitian dan Pembahasan}

Bimbingan dan Konseling adalah salah satu aspek penting dalam penyelengaraan pendidikan disekolah. Dalam prosesnya tentu tidak berjalan mulus saja tentu ada kendala atau hambatan yang dialami oleh warga sekolah khusus nya peserta didik baik berupa hubungan pribadi, sosial, belajar maupun karier. Tidak hanya itu pengembangan potensi, penelususuran minat dan bakat, memfasilitasi setiap perkembangan peserta didik juga merupakan tugas dari guru BK/ Konselor. Tugas guru BK di sekolah sangatlah kompleks, tentu untuk itu diperlukan media teknologi agar memudahkan guru BK/ Konselor dalam melaksanakan tugas nya disekolah.

Hal tersebut senada dengan pendapat yang disampaikan oleh (Setiawan 2016) mengatakan bahwa kemajuan Teknologi dan Informasi memberikan kemudahan dalam berbagai hal, misalnya dapat mempermudah proses komunikasi, serta menghemat biaya jika ingin melakukan hubungan dengan orang lain yang jaraknya jauh. Karakteristik utama dari Teknologi dan Informasi itu sendiri mencakup software dan hardware yang digunakan untuk memperoleh, menyebarkan, memproses ataupun menyimpan berbgai informasi yang 
bermanfaat dan dibutuhkan. Selain dari pada itu kondisi saat ini yang berada dalam masa pandemi covid media teknologi menjadi media/alat yang sangat penting dalam penyelenggaraan layanan bimbingan dan konseling karena tidak bisa dilaksanakan secara tatap muka.

Dalam layanan karier pemanfaatan media memberikan kemudahan bagi seseorang untuk menemukan koneksi atau informasi melalui jejaring sosial terkait dengan pengembangan karier mereka melalui pola interaksi yang dibangun. Hal ini sejalan dengan penelitian yang dilakukan oleh (Nancy Richmond 2015) yang mengatakan bahwa individu berkomunikasi dan berinteraksi melalui penggunaan status jejaring sosial untuk pengembangan karier serta mengekplorasi pilihan karier, belajar, membuat koneksi, mencari pekerjaan pengembangan keprofesionalan, membuat keputusan dan mempertahan citra profesionalitas melalui peran situs jejaring sosial.

Salah satu pemanfaatan teknologi dalam BK Adalah pelaksanaan Konseling secara online (e-counseling). Haberstroh dan Duffey (Isna Ni'matus Sholihah 2020) berpendapat bahwa konseling online merupakan upaya konselor untuk membantu menyelesaikan masalah melalui komunikasi secara online dengan chatting ataupun streaming video dan audio.

\section{Pentingnya E-Counseling dalam Layanan BK di Masa Pandemi Covid 19}

Terjadinya pandemi Covid 19 mengubah kehidupan manusia dari yang biasanya. Akibat pandemi banyak aspek yang menjadi sasarannya mulai dari ekonomi, pendidikan, politik dan bahkan menyasar kapada individu itu sendiri yaitu dampak psikologis. Semua aktivitas manusia harus berpindah dari yang tatap muka (bertemu lansung) menjadi tatap maya (Online) termasuk dunia pendidikan sendiri. Kondisi ini mempengaruhi kondisi psikologis anak dalam melaksanakan proses pembelajaran. Dalam penelitian yang dilakukan oleh Palupi (Abdullah Rasyid \& Abdul Muhid 2020) mengatakan bahwa selama pembelajaran via daring saat pandemi Covid 19 tingkat stress siswa sekolah dasar kelas 4-5 lebih tinggi dibandingkan tingkat stres siswa sekolah dasar kelas 1-3 dimana penelitian ini dilakukan dengan melibatkan subjek untuk kelas 1-3 sebanyak 42 orang sementara kelas 4-5 sebanyak 48 orang sehingga total responden sebanyak 90 orang.

Dampak stres akibat pembelajaran online tidak hanya dirakan oleh siswa SD Saja, akan tetapi mahasiwa pun yang sudah tergolong dewasa juga merasakan tress akibat pembelajaran daring. Hal ini sejalan dengan penelitian yang dilakukan oleh (Kusumawati 2020) memaparkan bahwa pembelajaran daring selama pandemi berdampak pada stress akademik mahasiswa, dimana penelitian ini melibatkan 285 orang mahasiswa dipulau jawa. Selain dari itu diterapkan nya kebijakan social distancing bagi individu juga menyebabkan terjadinya tress. Hal tersebut sejalan dengan penelitian yang dilakukan oleh (Mahmudah 2020) mengatakan bahwa dengan adanya kebijakan social Distancing terdapat dampak psikologis terhadap siswa diantaranya keefektifan belajar menjadi berkurang, perkembangan yang lambat, kurangnya interaksi sosial, kecemasan, dan melemahnya kekebalan tubuh.

Jika kita lihat kondisi saat ini dimana sudah memasuki era digitalisasi yang mana semua kegiatan manusia tersentral melalui media dan teknologi seperti yang dijelaskan oleh (Mintasih 2016) bahwa generasi saat ini dalam hidupnya tidak terlepas dari teknologi, bagi mereka kecanggihan teknologi adalah hal yang biasa. Tentunya dengan kondisi tersebut BK sebagai salah satu aspek penting dalam menyelanggarakan pendidikan harus mampu merespon itu semua salah satunya dengan memanfaatkan teknologi berupa layanan $E$ Counseling. Sehingga dengan adanya layanan E-Counseling tersebut dapat mempermudah konselor dalam melaksanakan layanan Konseling dimanapun dan kapanpun ditambah lagi saat ini kondisi pandemi yang tidak memungkinkan untuk melaksanakan konseling secara 
tatap muka. Wibowo (Abdullah Rasyid \& Abdul Muhid 2020) menjelaskan bahwa $e$ counseling dapat memudahkan konselor dalam dalam membantu konselinya. Melalui teknologi dapat membantu dan memudahkan konseli serta memberikan kenyamanan konsel dalam bercerita sehingga E-Counseling saat ini bukan hanya sebagai alternatif saja melainkan sudah menjadi kewajiban mengingat tidak memungkinkannya pelaksanaan konseling secara tatap muka lansung selama masa pandemi covid 19.

\section{Tahapan Pelaksanaan E-counseling (Konseling Online)}

Tahapan proses penyelenggaraan konseling dapat dibagi menjadi tiga tahap Ifdil 2011 (Passalowongi 2021) yaitu :

1) Tahapan (Persiapan) mencakup aspek teknis penggunaan perangkat keras (hardware) seperti komputer atau laptop yang dapat terkoneksi dengan internet, headset, mic, webcam dan sebagainya. Sedangkan perangkat lunak (software) program-program yang mendukung dan akan digunakan, account dan alamat email. Selain itu kesiapan konselor keterampilan, kelayakan akademik, penilaian, secara etik dan hukum, kesusuaian isu yang akan dibahas serta tata kekola.

2) Tahapan (Proses Konseling) konseling online tidak jauh berbeda dengan tahapan proses konseling face to face tahapan (Prayitno : 2004) yakni tahap pengantaran, penjagaan, penafsiran, pembinaan dan penilaian namun dalam pelaksanaanya "kontinum flesksibel". Pada sesi konseling online lebih menekankan pada terentasnya masalah klien dengan cara melakukan bentuk pendekatan, teknik atau terapi yang digunakan.

3) Tahap (Pasca Konseling) pada tahap ini merupakan yang dilakukan penilaian pertama konseling akan sukses dengan ditandai dengan kondisi klien yang effictive daily living-EDL, kedua konseling akan dilanjutkan tatap muka face to face, keempat konseling akan dilanjutkan pada sesi konseling onine berikutkan dan keempat klien dan direferal pada konselor lain atau ahli lain.

\section{Efektivitas pelaksanaan $\boldsymbol{e}$-counseling (Konseling Online)}

Pelaksanaan konseling selama ini dilaksanakan secara tetap muka yaitu bertemu lansung antara konselor dan konseli, namun kondisi saat ini selain dari perkembangan zaman yang semakin serba teknologi juga kondisi yang sedang mengancam kehidupan manusia pada masa pandemi covid-19 mengaruskan pelaksanaan konseling dilakukan secara online/ daring. Beberapa penelitian mengemukan bahwa hasil pelaksanaan konseling secara online dapat dikatakan dibutuhkan serta berhasil atau efektif dalam pelaksanaannya, diantaranya penelitian yang dilakukan oleh (Agrianur Rahman, Farida Aryanti 2018) menunjukkan bahwa Gambaran tingkat kebutuhan media video bimbingan konseling untuk mengurangi perilaku bullying siswa di SMAN 5 Makassar menunjukkan bahwa media video sangat penting dan dibutuhkan, Prototipe media video bimbingan konseling yang dikembangkan telah valid dan acceptable untuk mengurangi perilaku bullying, Keberterimaan media video bimbingan konseling yang diberikan kepada 10 siswa dalam uji kelompok kecil menunjukkan adanya perubahan tingkat perilaku bullying sebelum dan setelah penayangan media video bimbingan konseling.

Penelitian lain juga menyebutkan bahwa ada efektivitas yang berpengaruh dari konseling melalui media sosial WhatsApp terhadap perubahan pengetahuan, sikap, dan PHBS yang meningkat pada masyarakat ((Mulyati 2021). Pelaksanaan konseling online dinilai efektif dilaksanakan dalam membantu mengentaskan permasalahan siswa seperti dalam penelitian yang dilakukan oleh (Ifdil 2013) memaparkan bahwa konseling online cukup efektif untuk dilakukan dimana bagi konseli yang tidak memiliki kesempatan atau terkendala 
jarak, maka konseling online menjadi solusi dalam membantu mengentaskan permasalahan. Dalam penelitian yang dilakukan oleh fiin dan barak 2010 menyebutkan dalam penelitianya yang dilakukan terhadap 93 konselor memamparkan bahwa secara keseluruhan konselor online puas dengan praktek mereka dan percaya bahwa konseling online cukup efektif.

Penelitian yang dilakukan oleh (Moh. Fahri Yasin, FItri 2021) tentang efektivitas aplikasi zoom sebagai media e-cancelling fasilitas untuk mahasiswa kelas XI teknik laboratorium medik. Hasil penelitian menunjukkan bahwa penggunaan media Zoom sebagai sarana E-conseling bagi siswa kelas XI Teknik Laboratorium Medik SMK Bina Husada dikatakan efektif sebagai media e-conseling dalam program layanan e-konseling.

Pelaksanaan e-counseling di inggris menjadi perhatian dan kebutuhan bagi siswa sekolah, hal ini seperti yang disebutkan dalam penelitian yang dilakukan oleh (Hennigan 2016) mengatakan bahwa penyelenggaraan layanan terapi online diterima baik oleh siswa dan mendapat rekomendasi untuk dikembangkan lebih lanjut dalam proporsi yang sesuai dengan kebutuhan. Penelitian lain yang dilakukan oleh (Wiyono, Bambang D, Budi Purwoko 2020) mengatakan bahwa konseling online situs web dianggap "sangat bagus" dan diperoleh alternatif keputusan "sangat layak", serta Perkembangan dari situs web konseling online untuk memberikan layanan psikologis pendampingan selama Learning From Home (LFH) telah terpenuhi kriteria akseptabilitas, yaitu aspek kegunaan, akurasi, dan kelayakan.

Dalam penelitian yang dilakukan oleh (Amos, 2020) mengungkapkan bahwa manfaat konseling online sama dengan manfaat pelaksanaan konseling secara offline. Pada penelitian tersebut dikatakan bahwa pelaksanaan konseling baik secara online maupun ofline memiliki manfaat yang sama artinya walaupun dilaksanakan secara online konseling tetap berjalan secara efektif dan efisien sehingga masalah konseli dapat terentaskan dengan baik.

\section{Kesimpulan}

Pelaksanaan konseling selama ini dilaksanakan secara tetap muka yaitu bertemu lansung antara konselor dan konseli, namun kondisi saat ini selain dari perkembangan zaman yang semakin serba teknologi juga kondisi yang sedang mengancam kehidupan manusia pada masa pandemi Covid-19 mengaruskan pelaksanaan konseling dilakukan secara online/ daring. Berdasarkan hasil kajian literatur yang dilakukan bahwa pelaksanaan konseling secara online (e-counseling) efektif untuk membantu permasalahan yang dihadapi oleh siswa, dimana pada masa pandemi covid 19 ini banyak hambatan atau masalah yang dihadapi oleh siswa sehingga hal ini perlu direspon oleh guru BK / Konselor melalui pemberian layanan BK berbasis online (e-counseling).

\section{Saran}

Adapun saran yang dapat disampaikan berdasarkan studi literature ini adalah bagi Guru BK / Konselor agar lebih maksimal memanfaatkan layanan e-counseling dengan dukungan berbagai media sosial yang ada untuk membantu mengatasi masalah siswa. Selain itu, untuk penelitian berikutnya perlu dilakukan kajian lebih mendalam lagi tentang e-counseling dari tataran praktis dan meninjau dari aspek lainnya yang belum di bahas dalam penelitian terdahulu sehingga lebih pemperkuat hasil penelitian yang sudah ada.

\section{Daftar Pustaka}

Abdullah Rasyid \& Abdul Muhid. (2020). "Pentingnya E-Counseling dalam Pelayanan BK di Sekolah pada Masa Pandemi Covid 19.” EduPsyCouns Journal 2 (2). 
Agrianur Rahman, Farida Aryanti, Abdullah Sinring. (2018). "Pengembangan Media Video Bimbingan Konseling untuk Mengurangi Perilaku Bullying." Jurnal Psikologi Pendidikan \& Konseling Vol 4,No 2:129-36.

Amos, Patricia Mawusi. (2020). "Experiences of Online Counseling Among Undergraduates in Some Ghanaian Universities." Creative Commons CC-BY,Sage Pub.com 1-11.

Asmuni, A. (2020). Problematika Pembelajaran Daring di Masa Pandemi Covid-19 dan Solusi Pemecahannya. Jurnal Paedagogy, 7(4), 281-288. doi:https://doi.org/10.33394/jp.v7i4.2941

Hennigan, Jeanette \&. Stephen P. Goss. (2016). "UK secondary school therapists' online communication with their clients and future intentions." Counselling and Psychotherapy Research 16 (3):149-60.

Husni Abdillah, Punaji Setyo Sari, Blasius Boli Lasan, Muslihati. (2020). "The acceptance of school counselor in the use of ICT during school from home in the Covid-19 era." Journal for the Education of Gifted Young Scientists 8 (4):1569-82.

Ifdil, Ardi \&. (2013). "Konseling Online Sebagai Salah Satu Bentuk Pelayanan ECounseling." Jurnal Konseling dan Pendidikan 1 (1).

Isna Ni'matus Sholihah, Titin Handayani. (2020). "Pemanfaatan Teknologi dalam Layanan Bimbingan dan Konseling di Tengah Pandemi Covid 19." Hal. 478 in. Jawa Timur: PD ABKIN JATIM \& UNIPA SBY.

Kusumawati, Andiarna \&. E. (2020). "Pengaruh Pembelajaran Daring terhadap Stress Akademik Mahasiswa selama Pandemi Covid-19.” Jurnal Psikologi 16 (2).

Mahmudah. (2020). "Pengaruh Pembelajaran Daring terhadap Psikologis Siswa terdampak Social Distancing Akibat Covid 19." Al-Mau'izhoh 2 (2).

Mintasih. (2016). "Merancang Pembelajaran Menyengkan Bagi Generasi Digital." Jurnal ElTarbawi 9 (1).

Moh. Fahri Yasin, FItri, Iffah Budiningsih. (2021). "EFFECTIVENESS OF USING ZOOM MEDIA AS A MEANS OF E-COUNSELING STUDENTS OF GRADE XI MEDICAL LABORATORY ENGINEERING." Jurnal Teknologi Pendidikan 10 (1):113-22.

Mulyati, Imas Masdinarsyah. (2021). "Efektivitas Konseling Berbasis Media Sosial terhadap Perilaku Hidup Bersih dan Sehat." Jurnal Asuhan Ibu dan Anak Vol 6,No 1:41-50.

Nancy Richmond, Beth Rochefort and Leslie Hitch. (2015). "Using Social Networking Sites During the Career Management Process." Emerald Insight,Technologies in Higher Education Vol 2:147-64.

Passalowongi, Jaya Alam. (2021). "E-Councelling dalam Menangani Kasus Bullying di Sekolah." Jurnal Sipatokkong BPSDM 2 (1):24-34.

Setiawan, M. Andi. (2016). "PERANAN TEKNOLOGI INFORMASI DALAM BIMBINGAN DAN KONSELING." Bitnet Jurnal Pendidikan Teknologi Informasi Vol 1,No 1:46-49.

Triyono, Febriani, Rahmi Dwi. (2018). "PENTINGNYA PEMANFAATAN TEKNOLOGI INFORMASI OLEH GURU BIMBINGAN DAN KONSELING." Jurnal Wahana Konseling Vol 1,No 2:74-83.

Wiyono, Bambang D, Budi Purwoko, Najlatun Naqiyah. (2020). "Online Counselling Website for Student Psychological Assistance in Learning From Home." Advances in Social Science, Education and Humanities Research 491:1127-30. 